UCID- 21075

\title{
A HIGH GAIN FREE ELECTRON LASER AMPLIFIER DESIGN FOR THE ALCATOR-C TOKAMAK
}

R. A. Jong

February 1987

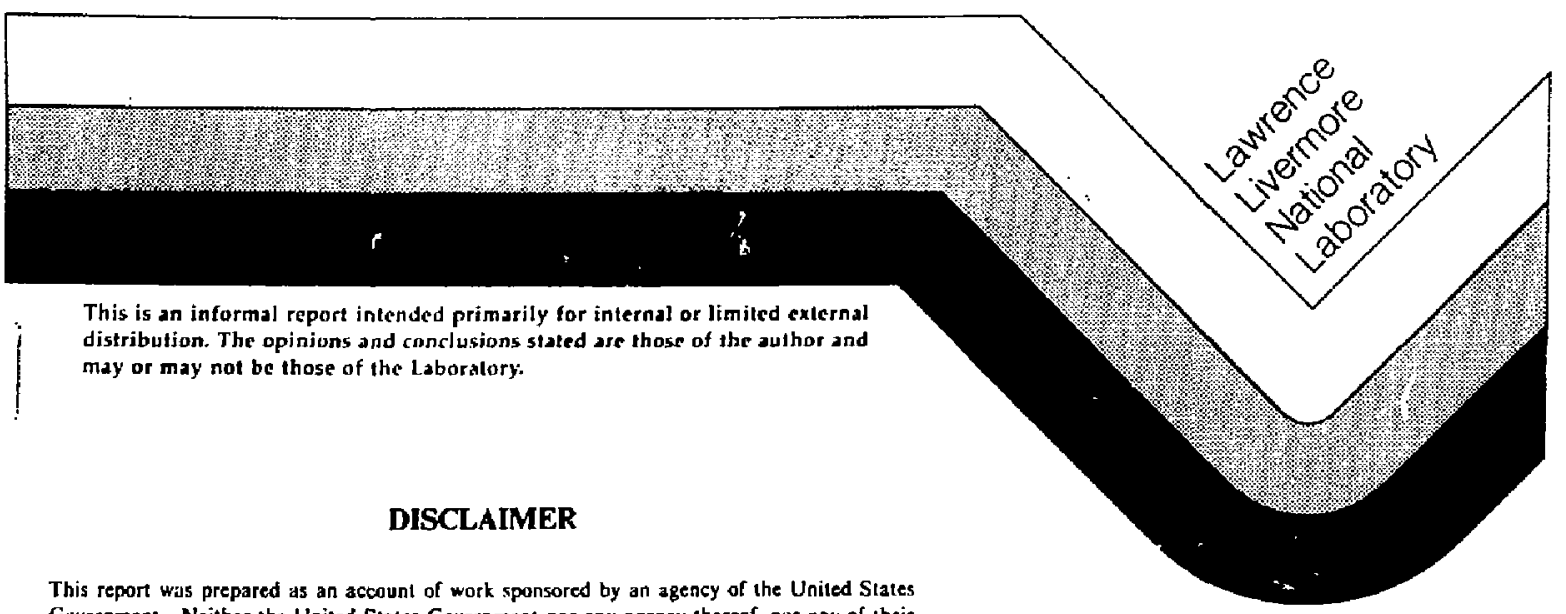

Government. Neither the United States Government nor any agency thereof, nur any of their employees, makes any wassanty, express or implied, or assumes any lega] liability or responsibility for the accuracy, completeness, or uselulness of any information, apparatus, product, or process diselosed, or represents that its use would not infringe privalely owned rights. Relerence herein to any specific commercial product, process, or service by trade name, trademark. manufacturer, or otherwise does not necessurily constitute or imply its endorsement, recommendation, or favoring by the United States Guvernment or any agency thereof. The views and opinions of authors expressed herein do not necessarily state or rellect those of the United States Government or any apency thereof. 


\section{A High Gain Free Electron Laser Amplifier Design for the Alcator-C Tokamak*}

$$
\text { R. A. Jong }
$$

Lawrence Livermore National Laboratory University of California. Livermore, California 94550

\section{Abstract}

We describe an improved wiggler tapering algorithm and the resulting wiggler design for a high-gain free electron laser amplifier to be used for plasma heating and current drive experiments in the Alcator-C tokamak. Unlike the original, this new design limits the growth of the shot noise to insignificant levels. The design goal of at least $8 \mathrm{GW}$ of peak power in the $T E_{01}$ mode was achieved with a $3 \mathrm{kA}$ electron beam with energies in the 7 to 9 $\mathrm{MeV}$ range and a beam brightness of $10^{5} \mathrm{~A} /(\mathrm{rad}-\mathrm{cm})^{2}$. The wiggler was 5 m long with a wiggler wavelength of $8 \mathrm{~cm}$.

UCID -21075

DE87 011600

\footnotetext{
*Work performed jointly under the auspices of the U.S. Department of Energy by Lawrence Livermore National Laboratory under contract W-7405-ENG-48, for the U.S. Army Strategic Defense Command in Support of SDIO/SDC-ATC MIPR No. W31RPO-7-04041.
}

\section{MASTER}

"DISTAIBUTION OF THS DOCUMENT IS UNLIMITEQ 


\section{Introduction}

In an earlier study $[1,2]$, we presented a preltminary design of a free electron laser for amplifying microwave radiation, with wavelengths in the 1 to $2 \mathrm{~mm}$ range, to be used for plasma heating and current drive experiments in the Alcator-C tokamak. This design study used the Lawrence Livermore National Laboratory, free electron laser simulation code, FRED [3]. It considered a $3 \mathrm{KA}$ electron beam with energies in the 7 to $10 \mathrm{MeV}$ range with brightness values of about $10^{5} \mathrm{~A} /(\mathrm{rad}-\mathrm{cm})^{2}$. The wiggler wavelength ranged from 8 to $9.8 \mathrm{~cm}$, and the overall wiggler length was 6 to $8 \mathrm{~m}$. With an input laser power of 50 to 100 watts, the peak output power at $250 \mathrm{GHz}$ in the $T E_{01}$ mode was in excess of $8 \mathrm{GW}$ for the $8.5 \mathrm{MeV}$ electron beam and $8 \mathrm{~m}$ long wiggler described in Ref. 2. A study [4] of the sicleband power produced by the wiggler designed for this FEL indicated that the design of Ref. 2 had a fatal flaw. The shot noise was amplified in the first several meters of the wiggler until the power at the fundarnental frequency was dominated by the power in the noise spectrum. This report describes the reasons why the original design was flawed and details the revised wiggler design that appears to have overcome the problems. The new wiggler design requires input laser powers of about 50 watts, and an electron beam with parameters just as in the original design ( $3 \mathrm{kA}$ current, 7 to $9 \mathrm{MeV}$ energy, $10^{5} \mathrm{~A} /(\mathrm{rad}-\mathrm{cm})^{2}$ brightness). However, the new wiggler is only $5 \mathrm{~m}$ long with a wiggler period of $8 \mathrm{~cm}$. 


\section{Original Wiggler Design}

In the original wiggler design [2], 50 watts of input laser power at a frequency of $250 \mathrm{GHz}$ were amplified to $10.4 \mathrm{GH}$ of total swer $(8.9 \mathrm{GW}$ in the $T E_{01}$ mode) in an $8 \mathrm{~m}$ long wiggler with an $8 \mathrm{~cm}$ wiggler period. In that system, $39.5 \%$ of the power was extracted from a $3 \mathrm{kA}, 8.5 \mathrm{MeV}$ electron beam having a brightness of $10^{5} \mathrm{~A} /(\mathrm{rad}-\mathrm{Cm})^{2}$. Running FRED in its self-design mode produced the wiggler magnetic field profile shown in fig. 1. This plot shows a peak magnetic field of 5.5 kGauss in the first $2 \mathrm{~m}$ of wiggler being tapered down to a minimum value of $0.9 \mathrm{kGauss}$ at the end of $8 \mathrm{~m}$. The plot of the $\mathrm{TE}_{01}$ power as a function of axial position in Fig. 2, shows the exponential gain region in the first 4 meters of wiggler, the effects of synchrotron oscillations after saturation, and the peak $\mathrm{TE}_{01}$ power levels attained of about $9 \mathrm{GW}$.

When the magnetic field profile of Fig. 1 was used in the Lawrence Livermore Hational Laboratory free electron laser sfmulation code for sideband calculations, GINGER [4], the shot noise was found to amplify at a much larger rate than the fundamental, resulting in the series of power versus frequency plots at various axial positions shown in Fig. 3. In Fig. 3a, the shot noise is seen to be initially about 5 orders of magnitude smaller than the 50 watt fundamental signal at $250 \mathrm{GHz}$. Figure $3 \mathrm{~b}$ shows the power spectrum after $2 \mathrm{~m}$ of wiggler where the noise on the lower frequency side of the fundamental has grown to become comparable to the fundamental power. By $3.2 \mathrm{~m}$, as seen in Fig. 3c, the lower frequency noise signat is larger than the fundamental by several orders of magnitude. In $\mathrm{Fig}$. 3d the ratio of sideband power to total power is plotted, and shows that by the $\mathbf{3} \mathrm{m}$ position, almost all the power is in the sidebands. 
Since the assumptions inherent in the GINGER calculations summarized in Fig. 3 (the sideband power is small compared to the fundamental power), have been violated, we may question the quantitative result from this GINGER calculation, that the sideband power will grow larger than the fundamental power. However, the qualitative results lead us to the conclusion that the shot noise would grow to high levels with this wiggler configuration, and probably prevent the fundamental power from amplifying to the required $8 \mathrm{GW}$ level.

The reason that this wiggler configuration has failed is that the peak in the gain curve is too far away from the synchronous operating point chosen by the wiggler design algorithm in FRED. This shift of the peak gain point away from the synchronous point results because the FEL is operating in the collective or Raman regime where space charge effects are important [5]. In short, FRED designs the magnetic field taper so that a particular test particle (and an appreciable fraction of the remainfng particles in the simulation) will remain synchronous in the ponderomotive well and continuously give up energy to the radiation field. This algorithm works fine for an FEL operating in the single particle or Compton regime. However, in a Raman regime FEL, this choice of the magnetic field generally means that the FEL is operated too far from the peak in the gain curve. The result then is lower gain at the desired fundamental frequency, and enhanced gain at some other lower frequency. A typical detuning curve for the Alcator-C FEL is shown in Fig. 4. The power out from a $1 \mathrm{~m}$ lang constant wiggler is plotted in Fig. 4a as a function of the the magnetic field axpressed as a fraction of the resonant (synchronous) magnetic field for various driver frequencies while and the relative $\mathrm{TE}_{01}$ power is piotted in Fig. $4 \mathrm{~b}$. The curves in Fig. 4 were calculated using $\mathrm{FEL}$ parameters typical of the range scanned in the design study. It is clear that 
the peak gain occurs for magnetic fields that are smaller than the synchronous value (where aw/awres is unity). Moreover, this shift to smaller magnetic fields is larger and the overall gain is lower at the higher frequencies.

These detuning curves in Fig 4. also explain why the noise at frecuencies below the fundamental was amplified substantially more than the noise at frequencies above the fundamental. If the FEL were designed to operate at the synchronous point for a $200 \mathrm{GHz}$ driver, we see from Fig. 4 that a lower frequency (140 GHz in the example) would be operating at a larger overall gain and at a point closer to tts gain curve peak. Conversely, a higher frequency (280 GHz for example) would be operating at a lower overall gain at a point farther away from the peak in its gain curve. The resultant preferential gain of the shot noise at frequencies below the fundamental is thus obvious.

III. Revised Wiggier Design

\section{a. New Design Strategy}

The calculations for the new wiggler configuration were based on a different design strategy. The peak wiggler magnetic field was kept constant at a value corresponding to the maximum in the gain curve for the fundamental (250 $\mathrm{GHz}$ ) radiation for some optimum length of the wiggler. This peak magnetic field value was about $97 \%$ of the synchronous field value. After the fundamental power had been amplified to some high level many more orders of magnitude above the noise level (which was also amplifying, but at a lower gain), the tapering of the magnetic field was turned on with the usual FRED synchronous point algorithm. 


\section{b. Length of the Constant Wiggler Section}

The optimum length of the wiggler section where the peak magnetic field is kept constant at the value determined by the maximum in the gain curve is determined by the competition between two physical phenomena having opposing effects on the power amplification. If the length is too short, the fundamental power would not grow enough to be significantly larger than the noise levels, and a situation similar to the original design would ensue once tapering began. If the constant wiggler section is too long, then increased detrapping of the electrons from the ponderomotive well and synchrotron oscillations would limit the gain of the fundamental power once tapering began. This competition between the low gain for a short constant wiggler section, and the synchrotron oscillations for a long constant wiggler section can be seen in Fig. 5, where the power as a function of wiggler length for three cases with constant wiggler section lengths of 1,2 and $3 \mathrm{~m}$ are compared. Note the change in the vertical scale.

In Fig. 5a, we see a large gain in the first 1 m of wiggler where the wiggler field is constant at the peak in the gain curve. Beyond $1 \mathrm{~m}$, the magnetic field is tapered at the synchronous field value, and the gain is smaller. In Fig. 5b, the peak magnetic field is constant and the gain is large for the first $2 \mathrm{~m}$ of wiggler, and the power rises to about $200 \mathrm{MW}$ at the $2 \mathrm{~m}$ point, as compared to a power of 2 MH at this same axial position in fig 5a. In Fig. 5c, we show the results for a $3 \mathrm{~m}$ constant wiggler section. The constant wiggler section is clearly too long in this case, as synchrotron oscijlations have set in between 2 and 3 meters. When tapering begins after $3 \mathrm{~m}$, the power does not grow to as high a value as in $\mathrm{Fig}$. $5 \mathrm{~b}$, because more electrons have been detrapped from the bucket while traversing the constant wiggler region between 2 and 3 meters. 


\section{c. FRED Results for $7 \mathrm{MeV}$ Electron Beam}

The optimum length of the constant wiggler section also depends on the e]ectron beam energy. For a $7 \mathrm{MeV}$ beam, this length was found to be about $2 \mathrm{~m}$, as shown in Fig. 6 . Using this constant wiggler section length of $2 \mathrm{~m}$ and a beam energy of $7 \mathrm{MeV}$, the axial $\mathrm{TE}_{01}$ power profile of Fig. 7 was calculated by FRED. It indicates that $10_{i} \mathrm{GW}$ of power can be produced in a $5 \mathrm{~m}$ long wiggler having a wiggler wavelength of $8 \mathrm{~cm}$. This corresponds to an extraction efficiency of about $48 \%$. The plot of tha modal field power in Fig. 8 also indicates that over $98 \%$ of the total power is in the TE 01 mode.

From Fig. 7 we also see that the power level has grown from 50 watts to about $200 \mathrm{MW}$ at a rate of about $37 \mathrm{~dB} / \mathrm{m}$ in the first $2 \mathrm{~m}$ of constant wiggler where we operated near the peak of the gain curve. In addition, the lack of large power oscillations after saturation, that normaliy signify synchrotron oscillations, indicates that the length of the constant wiggler section and the subsequent magnetic field tapering have been well optimized.

The magnetic field profile generated by FRED for this calculation is shown in Fig. 9. The magnetic field is constant at 4.3 kGauss for the first 2 m of wiggler. It then rises to 4.5 kGauss as we switch to operating at the synchronous magnetic field and then tapers to .55 kGauss after 5 m of wiggler.

This tapering rate and the total length of $5 \mathrm{~m}$ for the wiggler clearly seen to be the optimum. We tried to decrease the axial magnetic field gradient and lengthen the wiggler by decreasing the tapering rate of the magnetic field. However, the decreased tapering rate merely resulted in larger synchrotron oscillations and increased electron detrapping from the ponderomotive wel1, a corresponding degradation in the output power, and very little change in the magnetic field gradient and wiggler length. In retrospect, this is what 
should have been expected. Since the bucket is decelerating at a rate that is proportional to the laser field strength and inversely proportional to the energy of the synchronous electrons, the large power amplification in the constant wiggler section implies that the tapering rate must be rapid in order to keep the synchronous electrons in the ponderomotive well once tapering begins.

This new strategy for designing the wiggler magnetic field appears successful in producing the required power gains and keeping the electrons trapped in the ponderomotive well. Figure 10 is a series of phase space plots at various axial and radial positions. It clearly indicates that most of the electrons get trapped and remain trapped in the bucket.

d. GINGER Results for 7 MeV Electron Beam

Using the magnetic field profile of Fig. 9 in GINGER produced the power spectra and relative sideband power profile [4] shown in Fig. 11. This is a clear improvement over the corresponding results from the original wiggler design shown previously in Fig. 3. The shot noise spectrum in Fig. 11a is comparable to the spectrum in Fig. 3a. However, at the $2 \mathrm{~m}$ axial position, the differences between the two wiggler designs are already evident. Because the new design operated at the peak in the gain curve for $250 \mathrm{GHz}$ radiation for the first $2 \mathrm{~m}$ of wiggler, the fundamental power is now nearly eight orders of magnitude larger than the noise leveis. This difference has resulted both from the improved gain of the fundamental signal as well as the markealy smaller gain of the noise. The peak noise levels in the new design are more than four orders of magnitude smaller than the corresponding noise levels in the original wiggler design, at this same $2 \mathrm{~m}$ axial position. 
The spectrum at the end of the $5 \mathrm{~m}$ wiggler (Fig. IIC) now shows the dominance of the fundamental frequency. The typical upper and lower sideband structure is evident, with peak power levels about four orders of magnitude smaller than the fundamental. The relative sideband power plot in Fig. 110 shows that by the end of the wiggler the sideband power is still a negligible fraction (.0004) of the total power.

\section{e. FRED Results for 8.5 MeV Electron Beam}

In the origina] wiggler design [2], achieving the design goal of at least $8 \mathrm{GW}$ peak power in the $T E_{01}$ mode requtred using an $\&$ m long wiggler with an electron beam energy of $8.5 \mathrm{MeV}$. In this report we have already shown that with different magnetic field design strategy, the design goal could be achieved with a $5 \mathrm{~m}$ long wiggler and a $7 \mathrm{MeV}$ electron beam energy. However, in the course of the calculations using the $7 \mathrm{MeV}$ beam, it was concluded that this operating point was quite sensitive to complitational noise resulting from small changes in the step size and small changes in the tapering rate. This phenomenon has been seen in other FREO calculations in which the parameters were such as to give a somewhat marginal operating point. Consequently, an operating point was calculated using an $8.5 \mathrm{MeV}$ electron beam energy, and was found to be more robust and less sensitive to computational noise.

The detuning curve for the $8.5 \mathrm{MeV}$ beam energy, Fig. 12, indicates that the peak in the gain curve occurs at a magnetic field value that is $96 \%$ of the synchronous magnetic field value. The optimum constant wiggler section length is again about $2 \mathrm{~m}$ as shown in Fig. 13. Using a beam energy of $8.5 \mathrm{MeV}$, we find an operating point which produces $10.6 \mathrm{GW}$ of power in the TE 01 mode. The plot of $T E_{01}$ power as a function of axial position is shown in Fig. 14. 
The gain in the exponential region is about $40 \mathrm{~dB} / \mathrm{m}$, and the overall extraction efficiency is about $42 \%$. The TEOI power comprised over $99 \%$ of the totai power output in this case.

We also see from Fig. 14, that although the constant wiggler section length has been optimized, we have not optimized the tapering rate as well in this case as we did for the $7 \mathrm{MeV}$ calculation. The initial tapering rate is probably too small, as synchrotron oscillations are evident between 2 and 3 meters. This lack of precise optimization is also evident in the phase space plots at various axial and radial positions in Fig. IJ. When compared to the corresponding $7 \mathrm{MeV}$ beam plots in Fig. 10, we note that for the $8.5 \mathrm{MeV}$ beam case, there is a greater energy spread in the electrons at the $3 \mathrm{~m}$ axial position, and a smaller fraction appear to have been decelerated and trapped in the bucket. Furthermore, near the end of the wiggler, a smaller fraction of the electrons appear to remain trapped in the bucket. However, since the outrist power goal was achieved, further optimization of the taper was not necessary.

The wiggler magnetic field profile calculated by FRED is shown in Fig. 16. The magnetic field is constant at 5.2 kGauss for the first $2 \mathrm{~m}$ and then rises to a peak of 5.4 kGauss, before tapering to .52 kGauss after $5 \mathrm{~m}$. This peak magnetic field is significantly larger than for the $7 \mathrm{MeV}$ operating point, as shown by the comparison in Fig. 17. The field strength for the $8.5 \mathrm{MeV}$ case is $21 \%$ larger in the first $2 \mathrm{~m}$ section of constant wiggler and the peak value $5520 \%$ larger. Since 5.5 kGauss is probably the practical upper limit on the peak magnetic field that can be achieved [6] for wiggler magnets with a wavelength of $8 \mathrm{~cm}$ and a gap spacing of about $3 \mathrm{~cm}$, the maximum beam energy that can be used in this wiggler design will probably be about $8.5 \mathrm{MeV}$. 


\section{f. GINGER Results for $8.5 \mathrm{MeV}$ Electron Beam}

The GINGER results using the magnetic field profile of Fig. 16 for the 8.5 MeV electron beam are sumarized in Fig. 18. As expected, the results are basically identical to those for the $7 \mathrm{MeV}$ beam described above and shown in Fig. 11. Only small differences in the actual power levels reached by the fundamental and the sidebands are evident. We conclude that the new design strategy will produce suftable operating points for the Alcator-C FEL which can achieve the design power goals for beam energy ranges from 3 to $8.5 \mathrm{MeV}$.

\section{Summary of Results}

The original wiggler design for the Alcator-C FEL was found to operate in the Raman regime and consequently, using the standard design method which was successful for FEL's operating in the Compton regine, it produced too much gain at frequencies below the fundamental of the $250 \mathrm{GHz}$ oriver, resulting in the uniaiceptably large amplification of the shot noise. This would prevent the fundamental power from amplifying from the 50 watt input to the desired 8 GW output. A new design strategy for Raman FEL's with weak space charge effects, which permitted the necessary amplification of the fundamental frequency while keeping the noise and sideband power levels small, was demonstrated. In the new design strategy, the peak wiggier magnetic field was held constant at a value corresponding to the peak in the gain curve for the fundamental frequency, for some optimized length of the wiggler. Then the magnetic field was set to the value for synchronous operation and allowed to taper in the ssual manner.

Using this procedure, we were able to use FREO to determine suitable operating points for the Alcator-C FEL which produced the requisite $8 \mathrm{GW}$ of output power in the $\mathrm{TE}_{01}$ mode using an electron beam current of $3 \mathrm{KA}$, and $\mathrm{a}$ 
brightness of $10^{5}$ Ai(rad-cm $)^{2}$, with beam energies in the 7 to $8.5 \mathrm{MeV}$ range. The wiggler was found to be $5 \mathrm{~m}$ long, with a wiggler pertod of $8 \mathrm{~cm}$. The peak magnetic field values ranged from 5.4 kGauss to .52 kGauss for the 8.5 Mev beam design while for the 7 Mev design, the peak fields ranged from 4.5 kGauss to .55 kGauss. As expected, the magnetic field requirements were larger for the 8.5 MeV case, and approach the 7 imits set by present day wiggler magnet designs.

\section{Acknowledgments}

W. M. Fawley discovered the shot noise problem with the original Alcator-C FEL wiggler design and also performed the GINGER calculations for the subsequent revised designs. E. T. Scharlemann suggested the new design strategy for Raman FEL's which turned out to be very successful.

VI. References

1. R.A. Jong and E.T. Scharlemann, "High Gain Free Electron Laser for Heating and Current Drive in the ALCATOR-C Tokamak," presented at the Eighth International Free Electron Laser Conference, Glasgow, Scotland, September $1-5,1986$.

2. K.I. Thomassen, ed., "Free Electron Laser Experiments in Alcator C," Lawrence Livermore National Laboratory, LLL-PROP-00202, July, 1986.

3. T.J. Orzechowski, E.T. Scharlemann, B. Anderson, V.K. Nefl, H.M. Fawley, D. Prosnitz, S.M. Yarema, D.B Hopkins, A.C. Paul, A.M. SessTer, and J.S. Wurtele, "High-Gain Free Electron Lasers Using Induction Linear Accelerators," IEEE J. of Quantuin Electron, Vo1. QE-21, 831 (1985).

4. W.M. Fawley, private communication, october, 1986. 
5. E.T. Scharlemann, private communication, October, 1986 .

6. K. Halbach, private communication, May, 1986.

\section{Figure Captions}

1. Wiggler magnetic field profile for the original Alcator-C FEL design.

2. $T E_{01}$ mode fleld power profile for the original Alcator-C FEL design.

3. Power spectrum and relative sideband power plotted at various axial positions for the original Alcator-C FEL. (a) Sideband power at $z=.08 \mathrm{~m}$, showing the initial shot noise distribution. (b) Power spectrum at $z=2$. m position. (c) Power spectrum at $z=3.2 \mathrm{~m}$ position. (d) Plot of relative sideband power as a function of axial position.

4. Detuning curve for Alcator-C FEL showing power as a function of magnetic field, expressed as a fraction of the resonant (synchronous) magnetic field, for various driver frequencies. (a) $T E_{01}$ power versus relative

magnetic field. (b) Relative $T E_{01}$ power versus relative magnetic field.

5. $\mathrm{TE}_{01}$ field power plotted as a function of position in the wiggler for cases where the peak magnetic field is held constant at the maximum of the gain curve for different lengths. (a) Constant field length is $1 \mathrm{~m}$. (b) Constant field length is $2 \mathrm{~m}$. (c) Constant field lengtti is $3 \mathrm{~m}$.

6. Total power out of a $5 \mathrm{~m}$ long wiggler for the $7 \mathrm{MeV}$ beam case, plotted as a function of the length of the intial constant peak magnetic field (untapered) section of the wiggler.

7. $T E_{01}$ field power for the revised wiggler design, for an electron beam energy of $7 \mathrm{MeV}$, plotted as a function of axial position in the wiggler.

8. Modal field power for the revised wiggler design, for an electron beam energy of $7 \mathrm{MeV}$, plotted as a function of axial position in the wiggler. 
9. Higgler magnetic field profile for the revised wiggler design. For an electron beam energy of $7: y e V$, plotted as a function of axial position.

10. Phase space plots at various axial and radial positions for the $7 \mathrm{MeV}$ electron beam wiggler design showing the trapping of the electrons in a ponderomotive well. (a) Phase plat at $z=1$. m position. (b) phase plot at $z=2$. m position. (c) Phase plot at $z=3$. m position. (d) Phase plot near the end of the wigg!er at $z=4.9 \mathrm{~m}$ position.

11. Power spectrum and relative sideband power plotted at various axial positions for the $7 \mathrm{MeV}$ electron beam FEL design. (a) sideband power at $z=.08 \mathrm{~m}$, showing the initial shot noise distribution. (b) Power spectrum at $z=2$. m position. (c) Power spectrum at the end of the wiggler at the $z=5.04 \mathrm{~m}$ position. (d) Plot of relative sideband power as a function of axial position.

12. Detuning curve for Alcator-C FEL with an $8.5 \mathrm{MeV}$ electron beam showing total and $\mathrm{TE}_{01}$ power at $250 \mathrm{GHz}$ as functions of the magnetic field. expressed as a fraction of the resonant (synchronous) magnetic field.

13. Total power out of a 5. m long wiggler for the $8.5 \mathrm{MeV}$ beam case, plotted as a function of the length of the initial constant peak magnetic field section of the wiggler for various taper parameters (psiro).

14. $\mathrm{TE}_{01}$ field power for the revised wiggler design, for an electron beam energy of $8.5 \mathrm{MeV}$, plotted as a function of axtal position in the wiggler.

15. Phase space plots at various axial and radial positions for the $8.5 \mathrm{MeV}$ electron beam wiggler design showing the trapping of the electrons in a ponderomotive well. (a) Phase plot at $z=1$. m position. (b) phase plot at $z=2$. m position. (c) Phase plot at $z=3$. m position. (d) Phase plot near the end of the wiggler at $z=4.9 \mathrm{~m}$ position. 
16. Wiggler magnetic field profile for the revised wiggler design, for an electron beam energy of $8.5 \mathrm{MeV}$, plotted as a function of axial position.

17. Comparison of the peak wiggler magnetic field strengths and normalized vector potentials for the $7 \mathrm{MeV}$ and $8.5 \mathrm{MeV}$ electron beam cases.

18. Power spectrum and relative sideband power plotted at various axial positions for the $8.5 \mathrm{MeV}$ electron bean FEL design. (a) Sideband power at $z=.08 \mathrm{~m}$, showing the initial shot noise distribution. (b) Power spectrum at $z=2$. m position. (c) Power spectrum at the end of the wiggler at the $z=5.04 \mathrm{~m}$ position. (d) Plot of relative sideband powar as a function of axial position. 


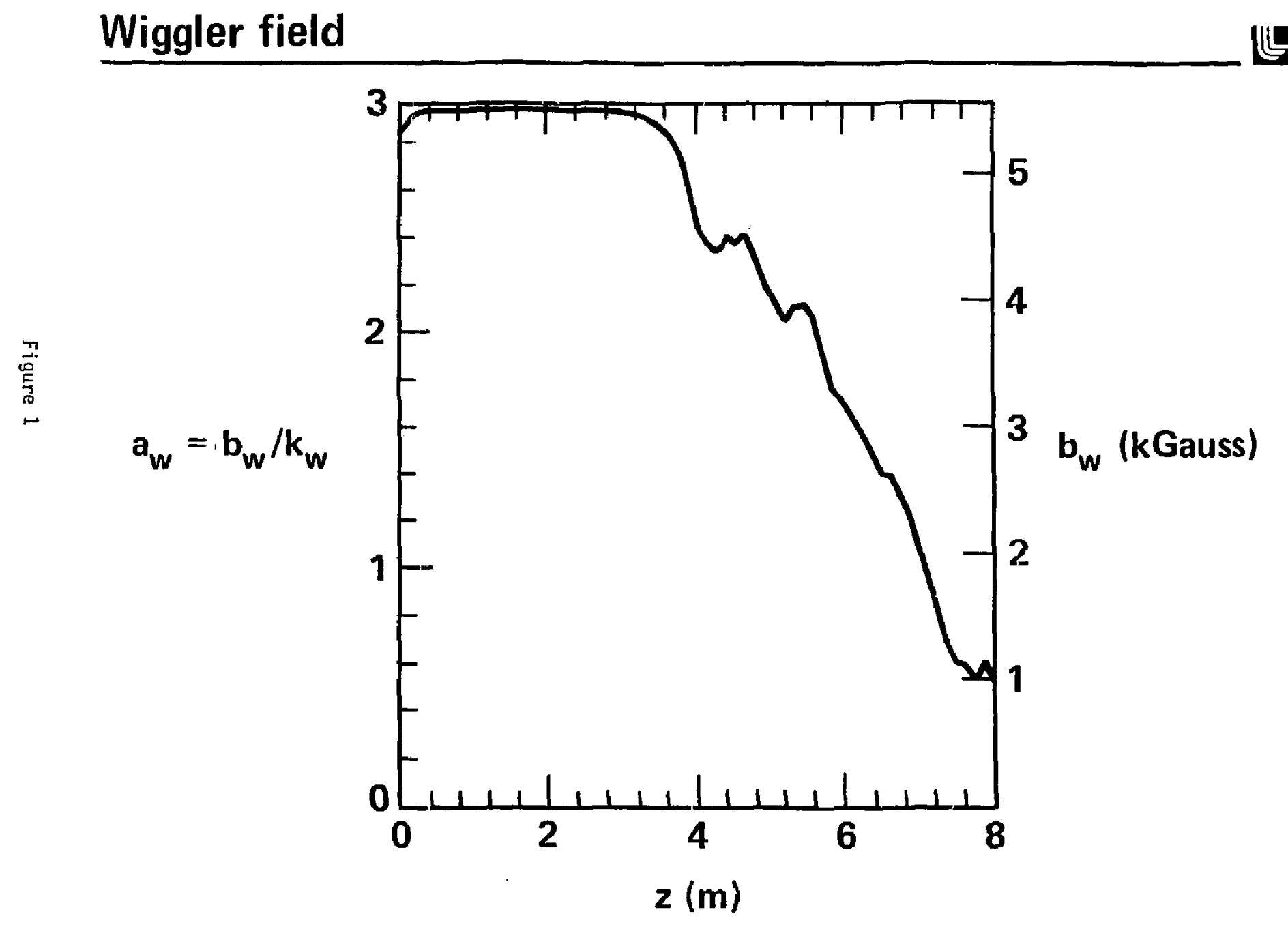

90-F-0287-0137 


\section{TE01 field power}

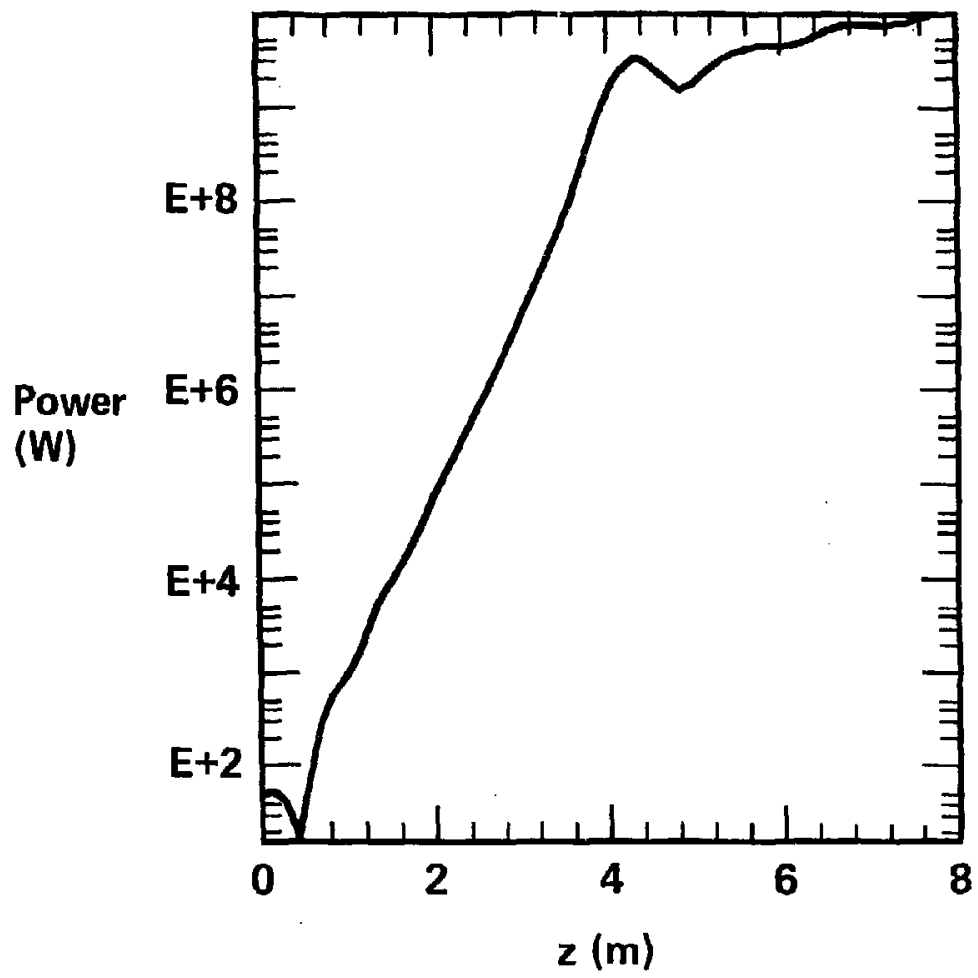

90-F.0287-0136B 
Sideband power at $Z=.08 \mathrm{~m}$

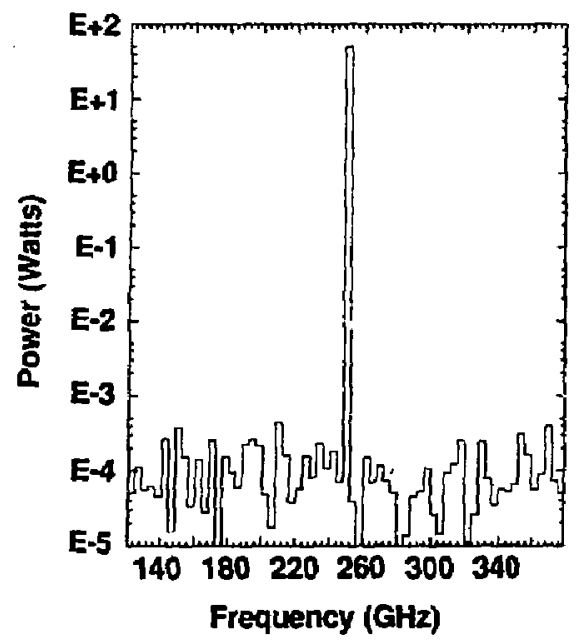

(a)

\section{1}

Output power at $Z=3.20 \mathrm{~m}$

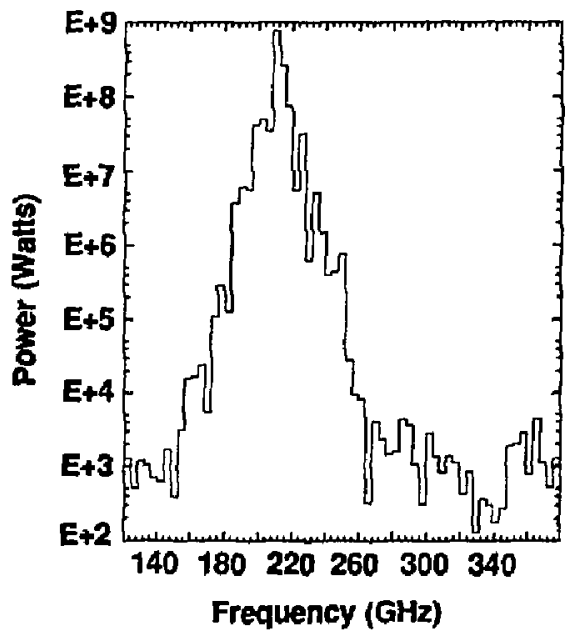

(c)
Sideband power at $\mathrm{Z}=\mathbf{2 . 0 0 \mathrm { m }}$

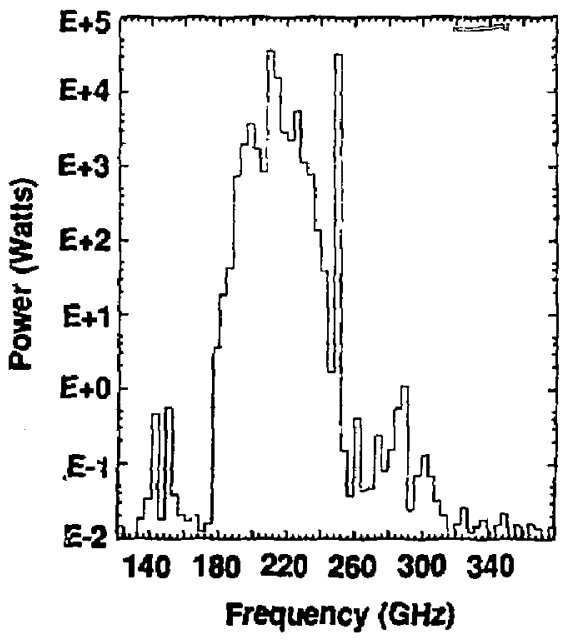

(b)

Relative sldeband power vs. $Z$

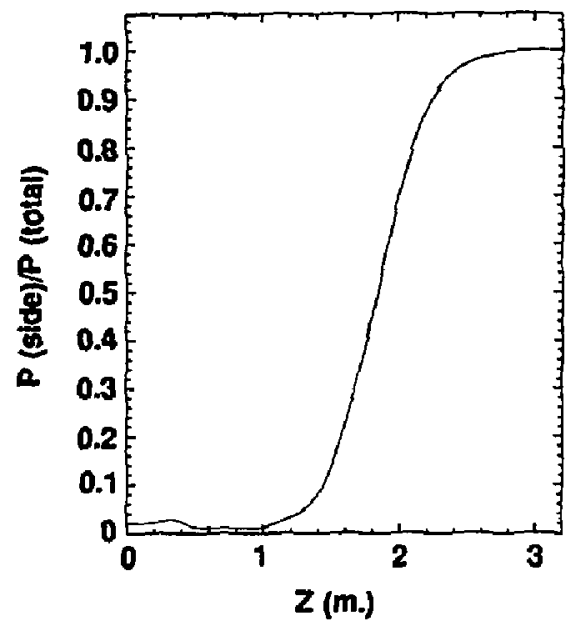

(d)

Figure 3 
Detuning curves for Alcator-C FEL

$10 \mathrm{MeV}, 3 \mathrm{kA}$ beam; $1 \mathrm{~m}$ long, $8 \mathrm{~cm}$ period wiggler; $1 \mathrm{E5} \mathrm{A} /(\mathrm{rad}-\mathrm{cm})^{2}$
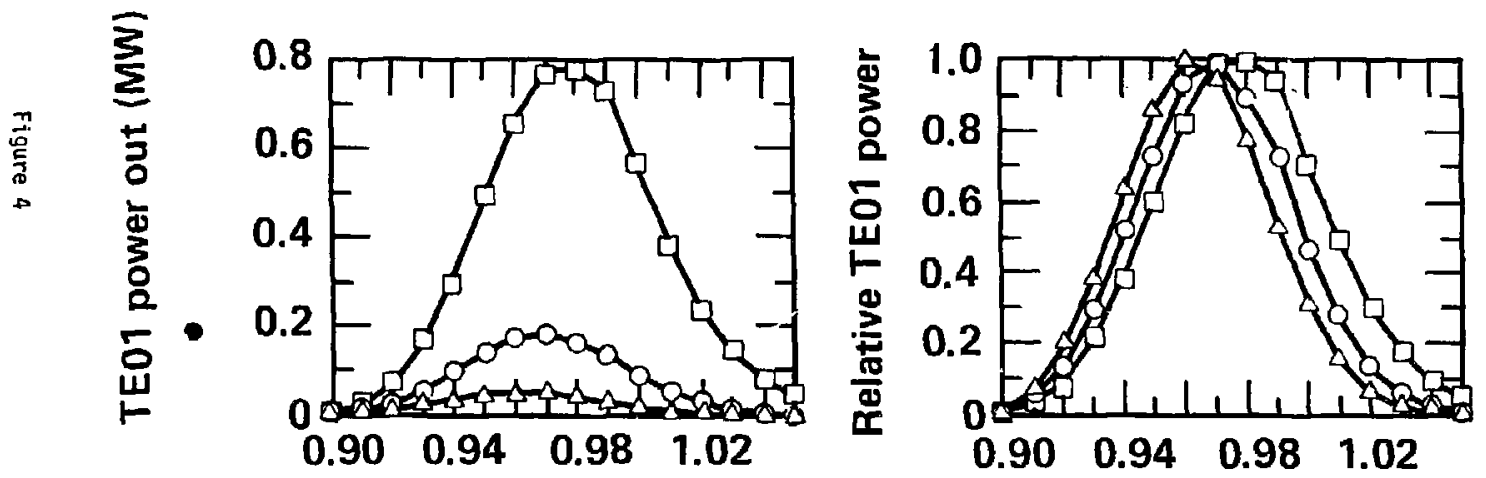

Fraction of synchronous magnetic field

$$
\square \mathrm{f}=140 \mathrm{GHz}
$$

$O f=200 \mathrm{GHz}$

$\Delta f=280 \mathrm{GHz}$ 


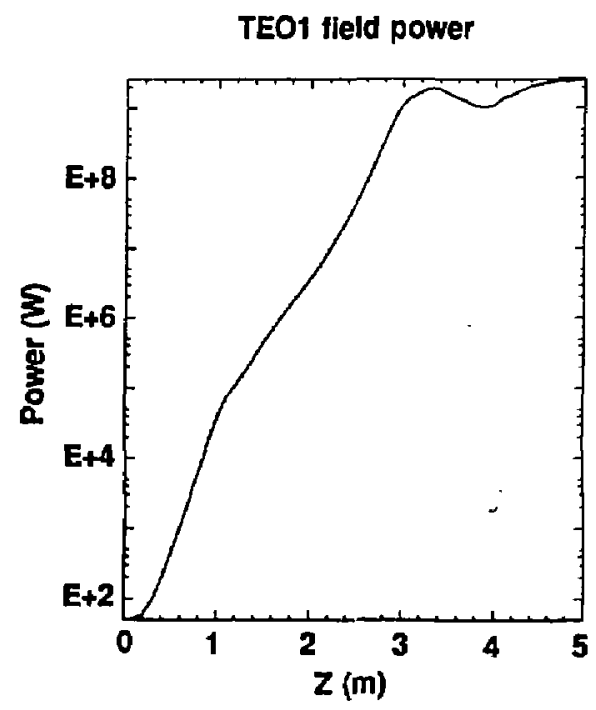

(a)

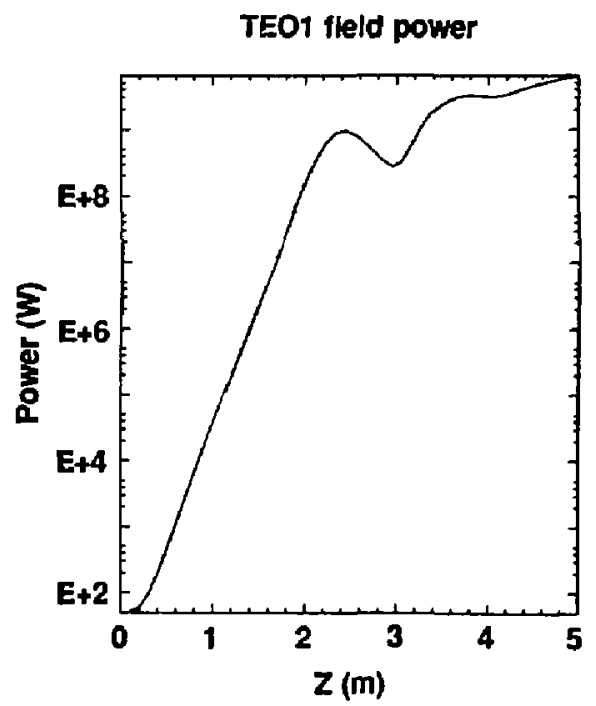

(c)
TEO1 fleld power

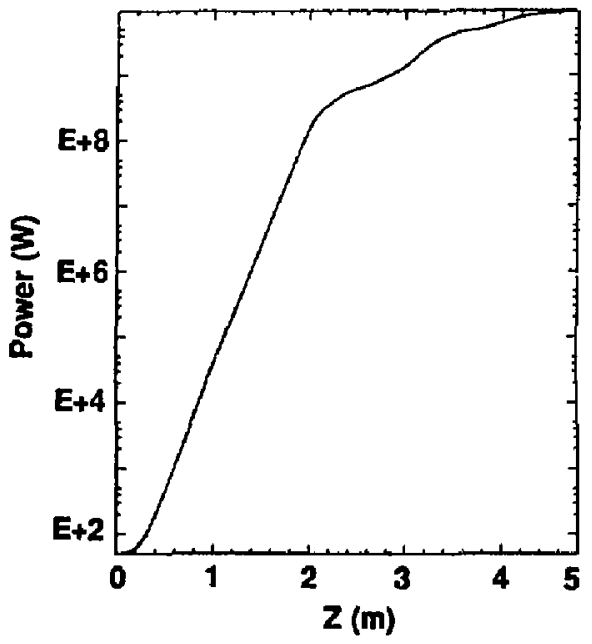

(b) 
Power out vs length of constant wiggler section

$7 \mathrm{MeV}, 3 \mathrm{kA}$ beam; $5 \mathrm{~m}$ long, $8 \mathrm{~cm}$ period wiggler; $1 \mathrm{E} 5 \mathrm{~A} /(\mathrm{rad}-\mathrm{cm})^{2}$

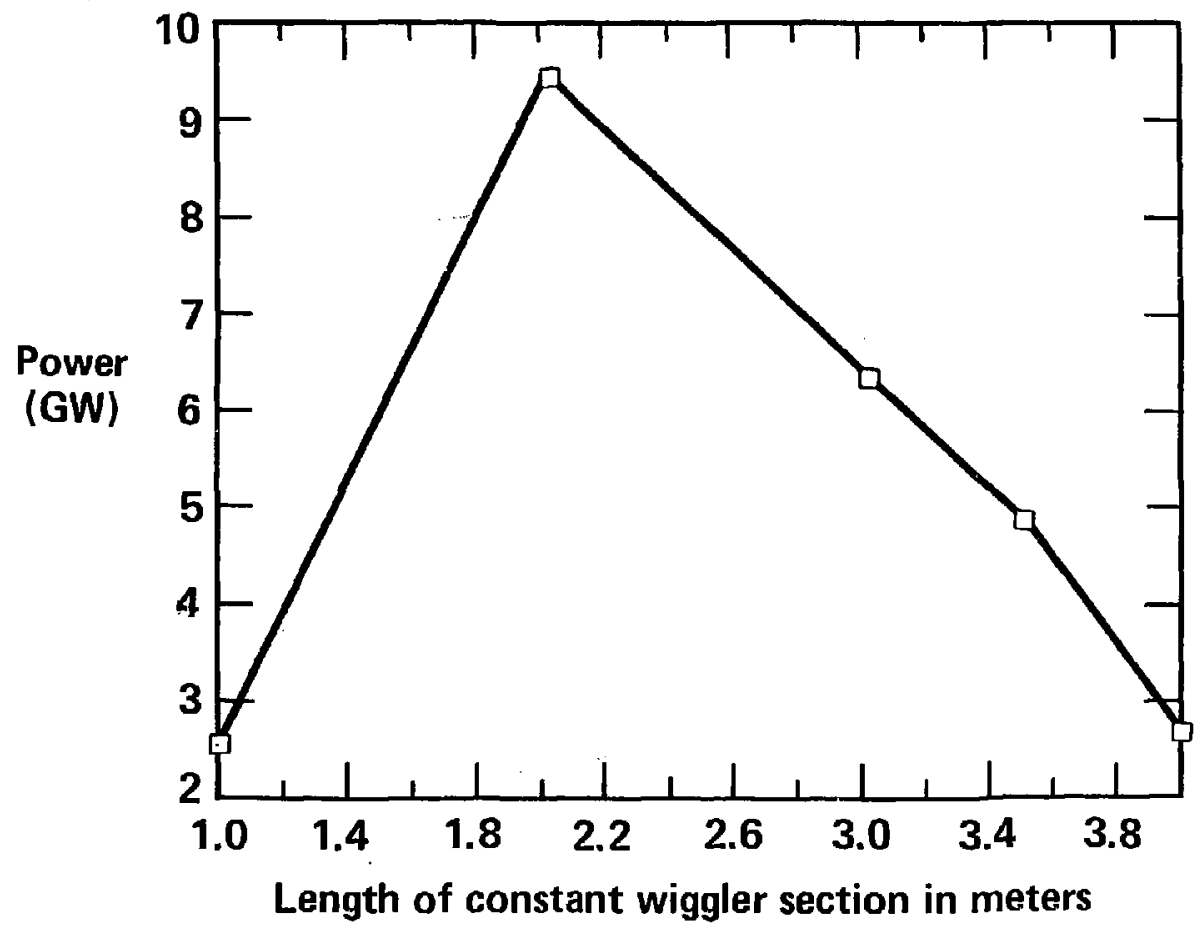

90-F-0287-0135 


\section{TE01 field power}

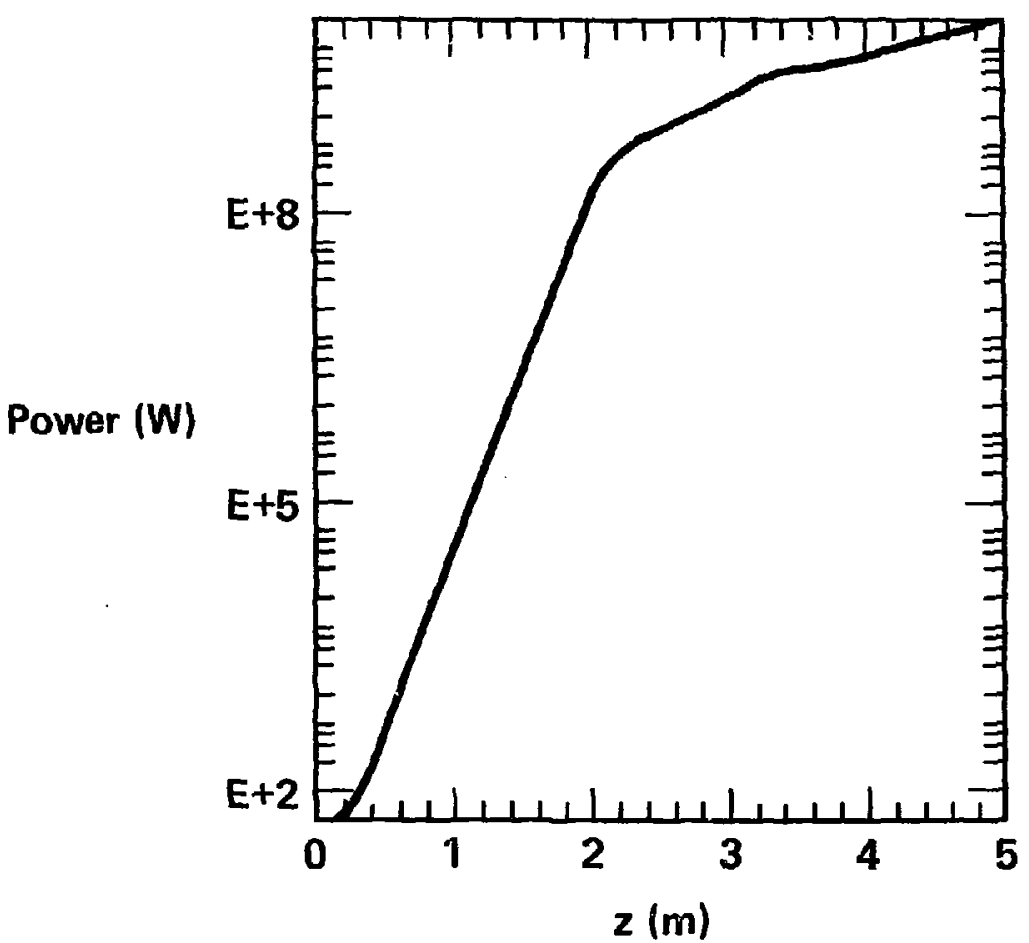




\section{Modal field power}

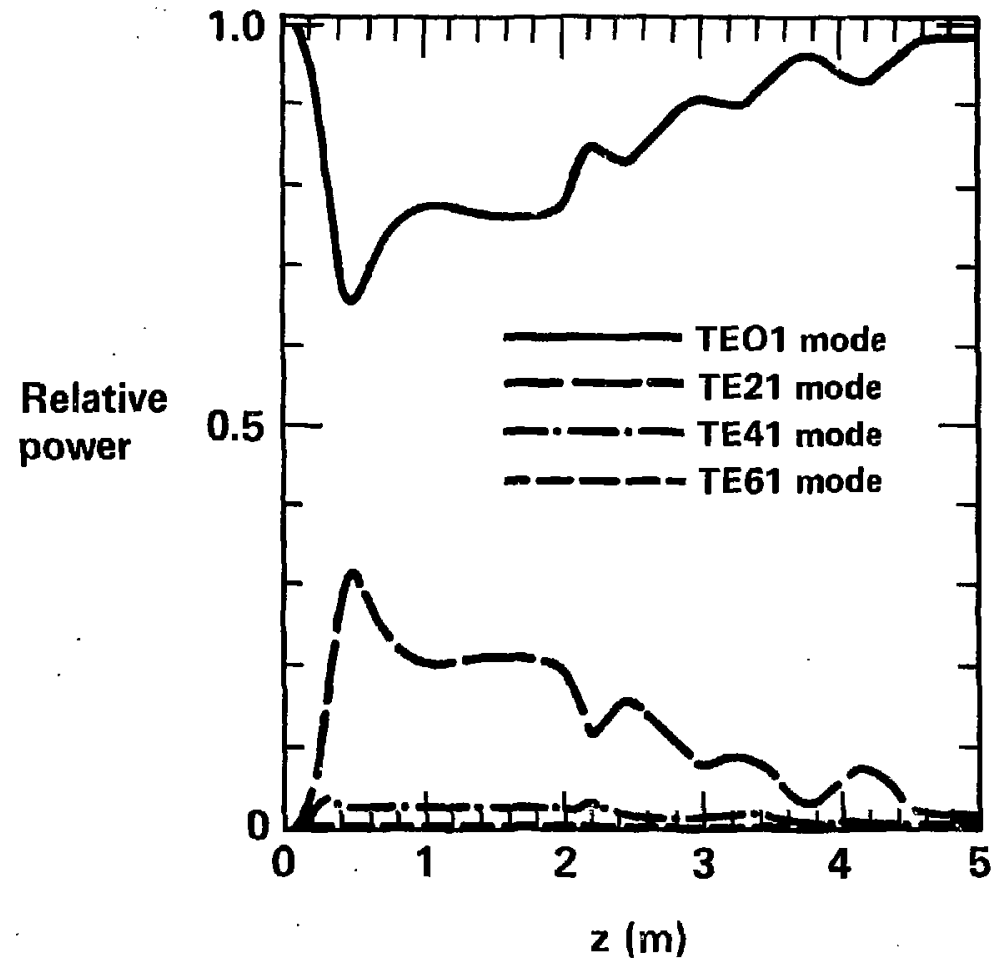

90-F-0287-0135B 


\section{Wiggler field}

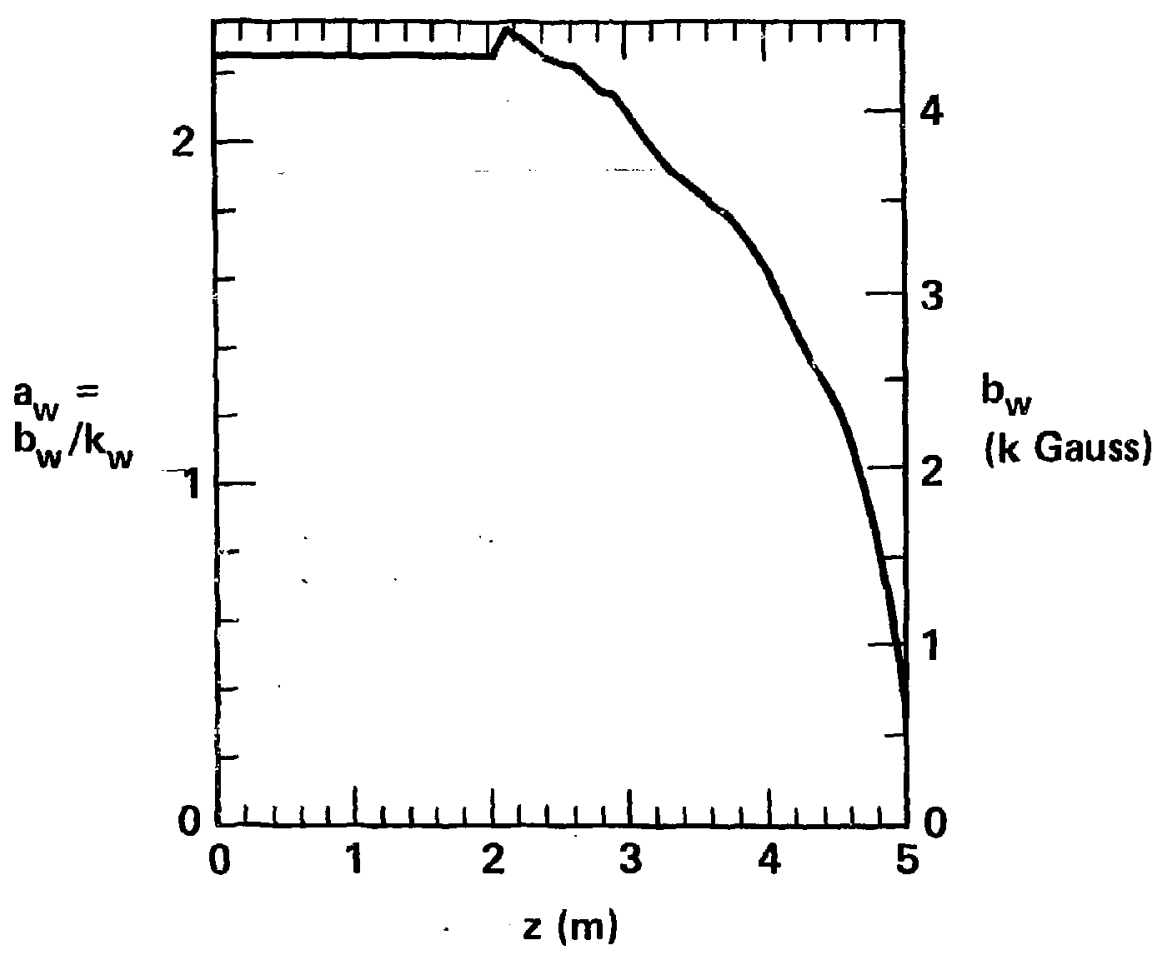

90-F-0287-0136 


\section{Phase space plots for $7 \mathrm{MeV}$ beam at various axial positions}

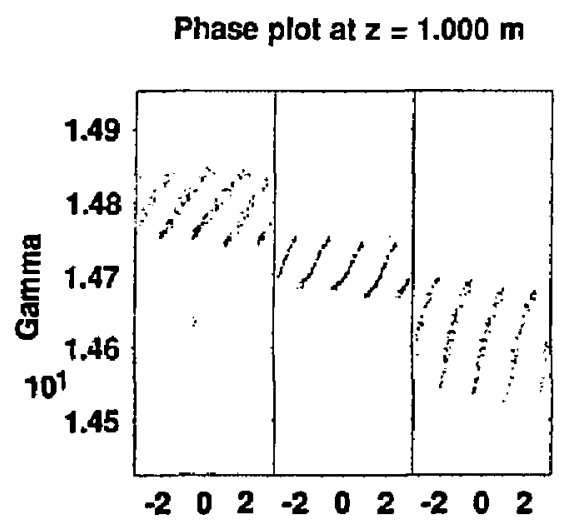

Psl (radlans)

(a)

Phase plot at $z=3.000 \mathrm{~m}$

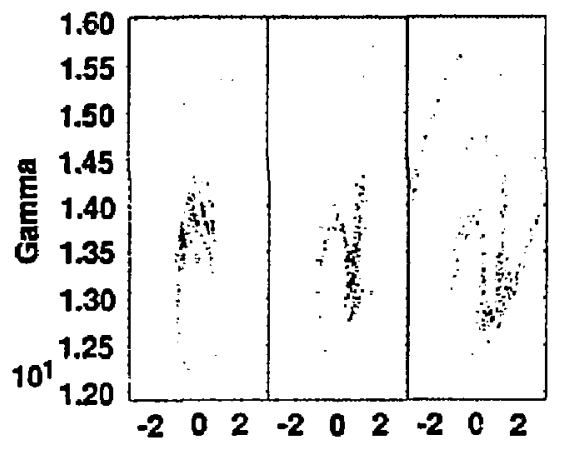

Psi (radians)

(c)
Phase plot at $z=2.000 \mathrm{~m}$

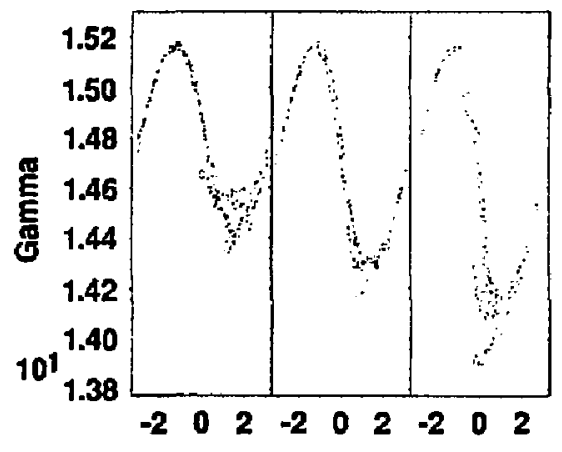

Psi (radians)

(b)

Phase plot at $z=4.900 \mathrm{~m}$

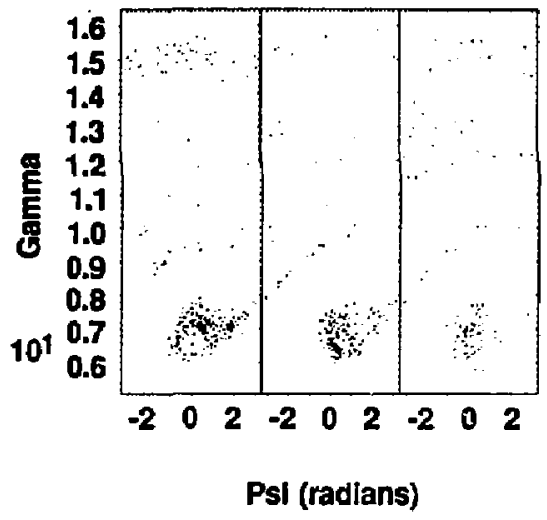

(d) 
Sideband power at $\gamma=.08 \mathrm{~m}$

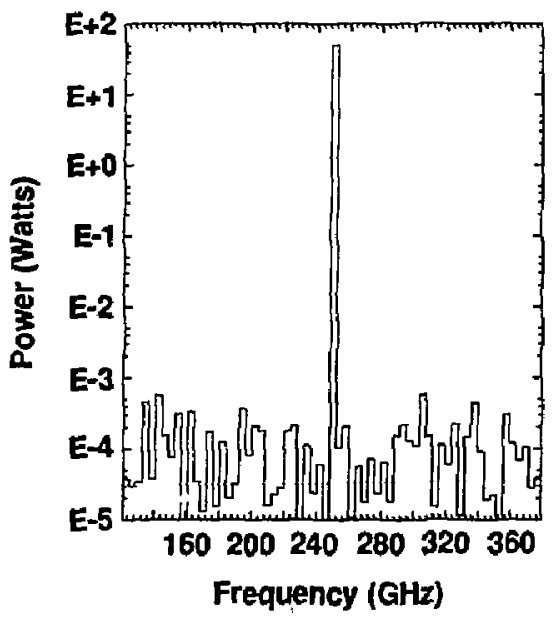

-(a)

Output power at $\mathrm{Z}=5.04 \mathrm{~m}$

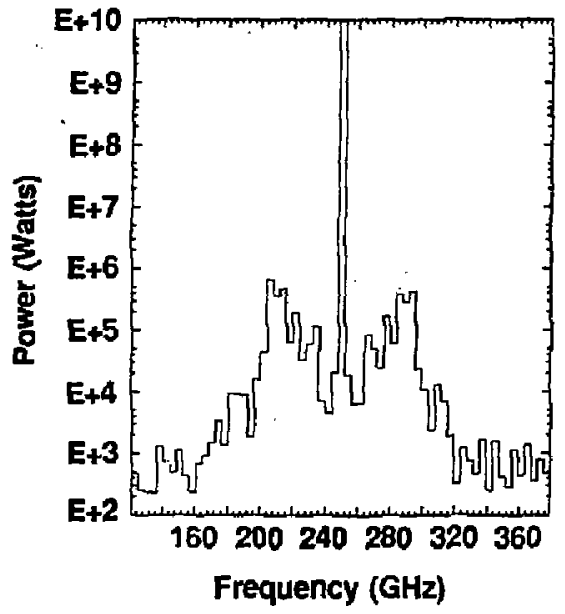

(c)
Sldeband power at $Z=2.00 \mathrm{~m}$

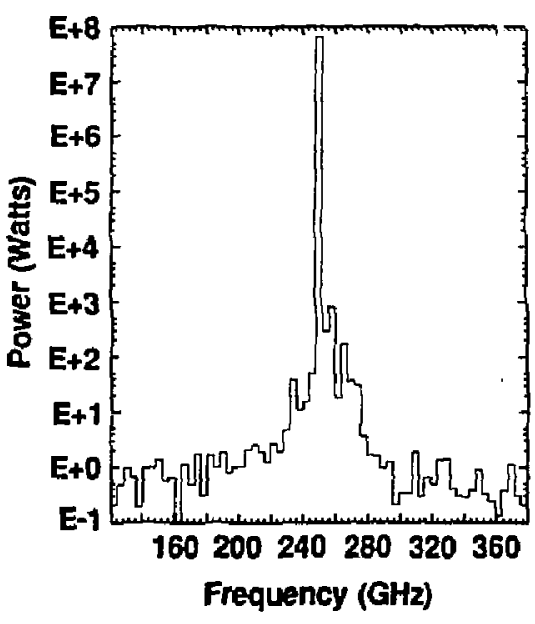

(b)

Relative sldeband power vs. Z

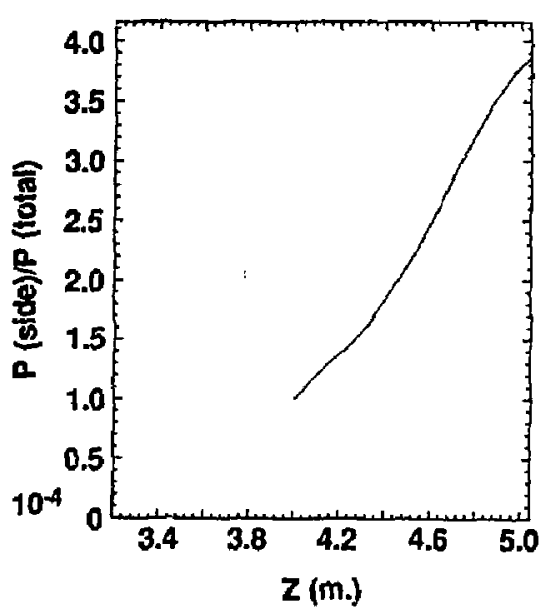

(d) 
$8.5 \mathrm{MeV}, 3 \mathrm{kA}$ beam; $1 \mathrm{~m}$ long, $8 \mathrm{~cm}$ period wiggler; $1 \mathrm{E5} \mathrm{A/(rad-cm})^{2}$

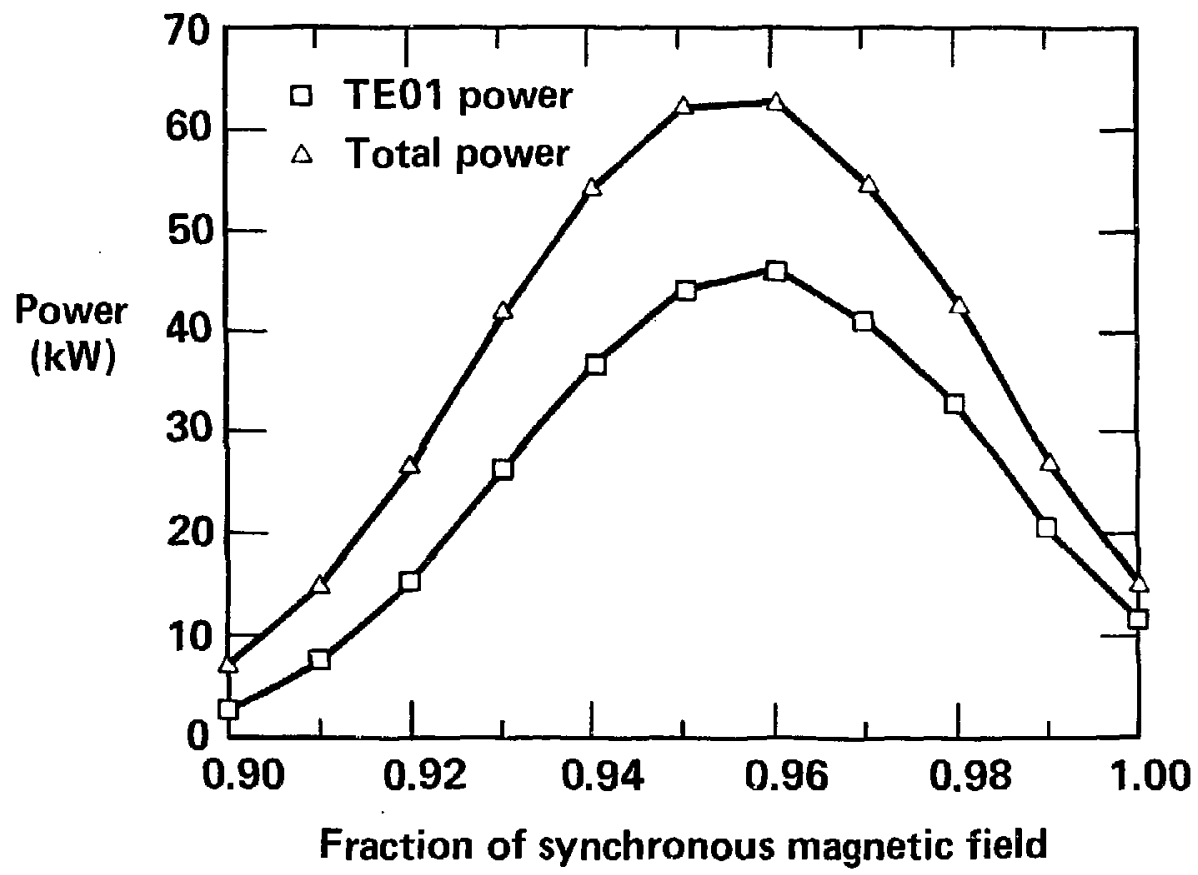

g0-F-0287-0136A 


\section{Power out vs length of constant wiggler section}

$8.5 \mathrm{MeV}, 3 \mathrm{kA}$ beam; $5 \mathrm{~m}$ long, $8 \mathrm{~cm}$ period wiggler; $1 \mathrm{E} 5 \mathrm{~A} /(\mathrm{rad}-\mathrm{cm})^{2}$

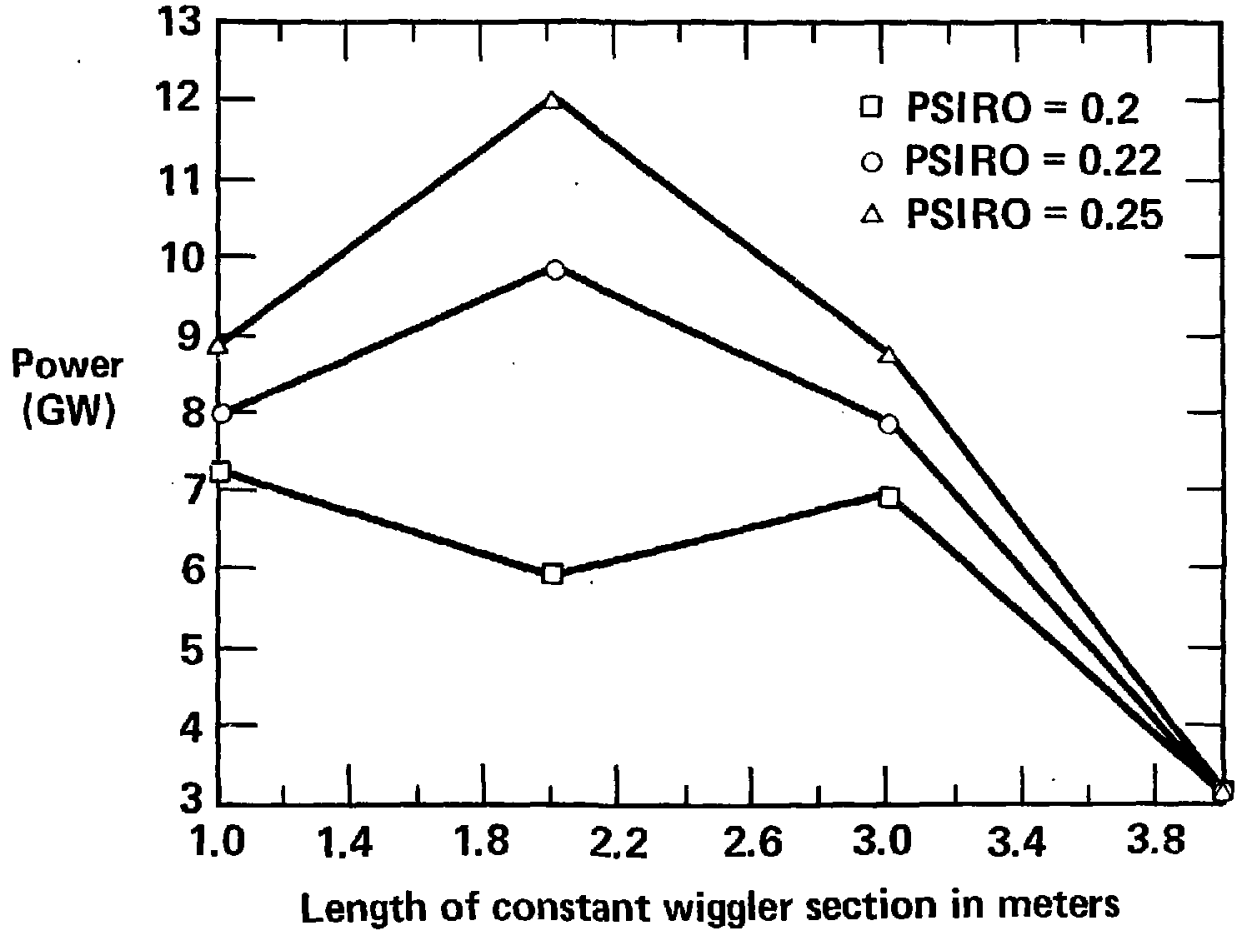




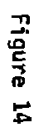

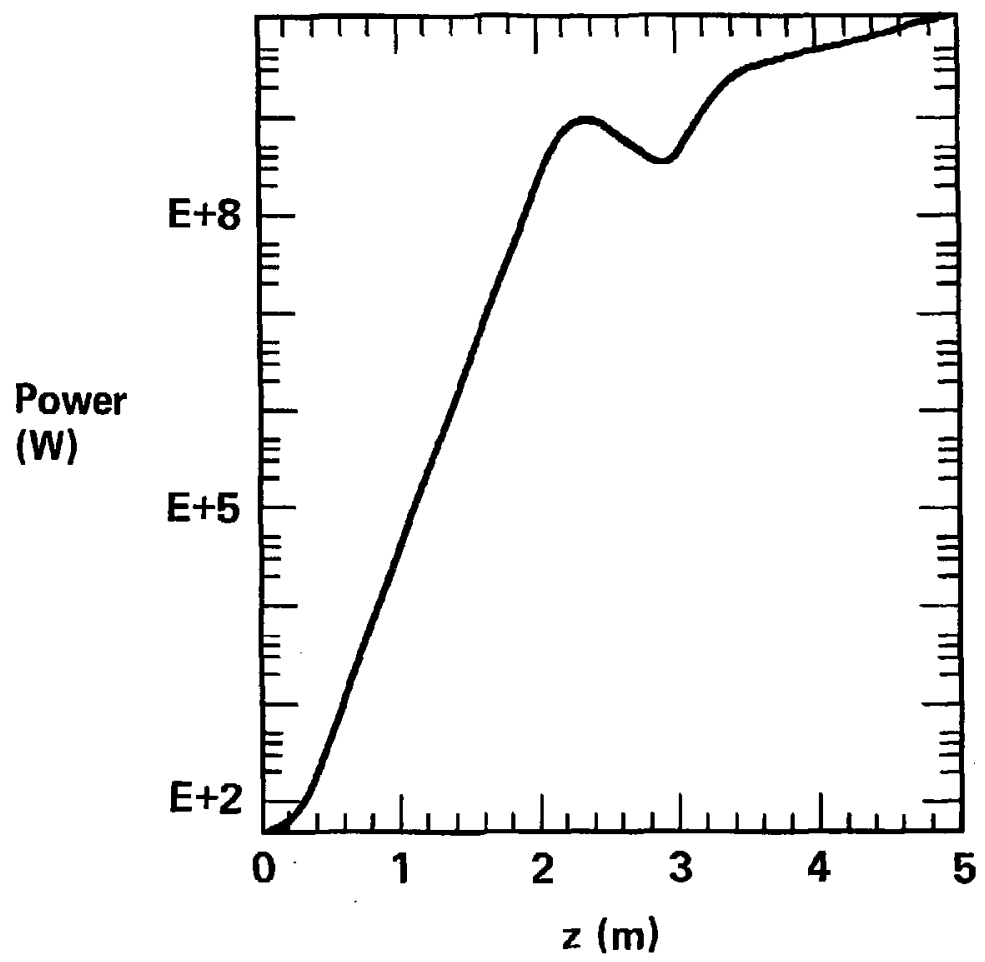

G0-F-0287-0134B 


\section{Phase space plots for $8.5 \mathrm{MeV}$ beam at various axial positions}

Phase plot at $z=1.000 \mathrm{~m}$

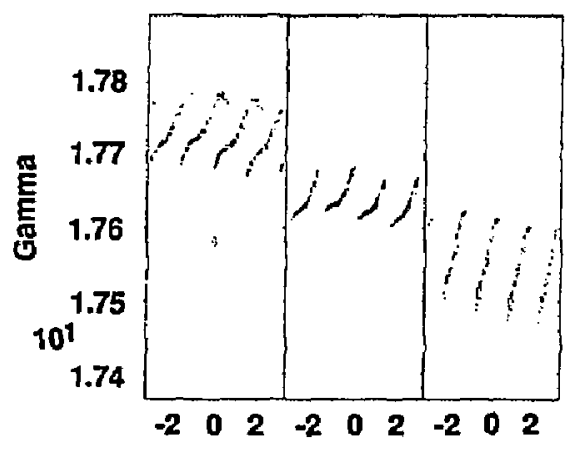

Psl (radians)

(a)

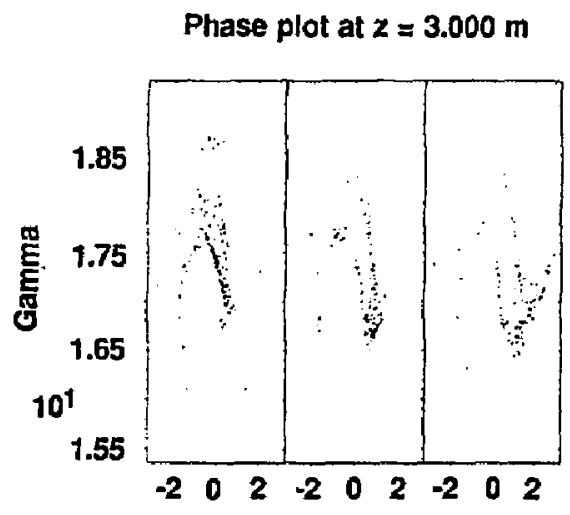

Psl (radians)

(d)
Phase plot at $z=2.000 \mathrm{~m}$

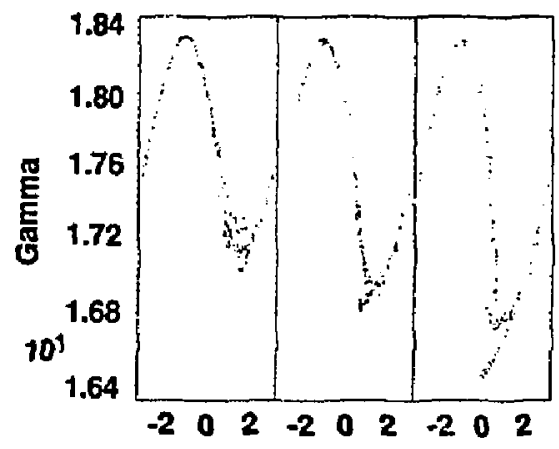

Psi (radlans)

(b)

Phase plot at $z=4.900 \mathrm{~m}$

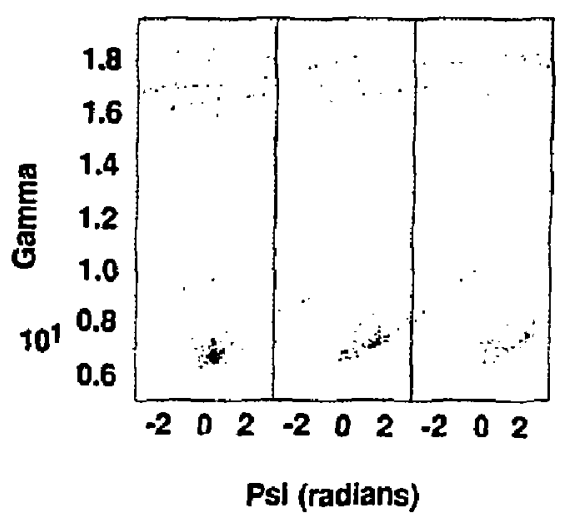

(c) 


\section{Wiggler field}

공

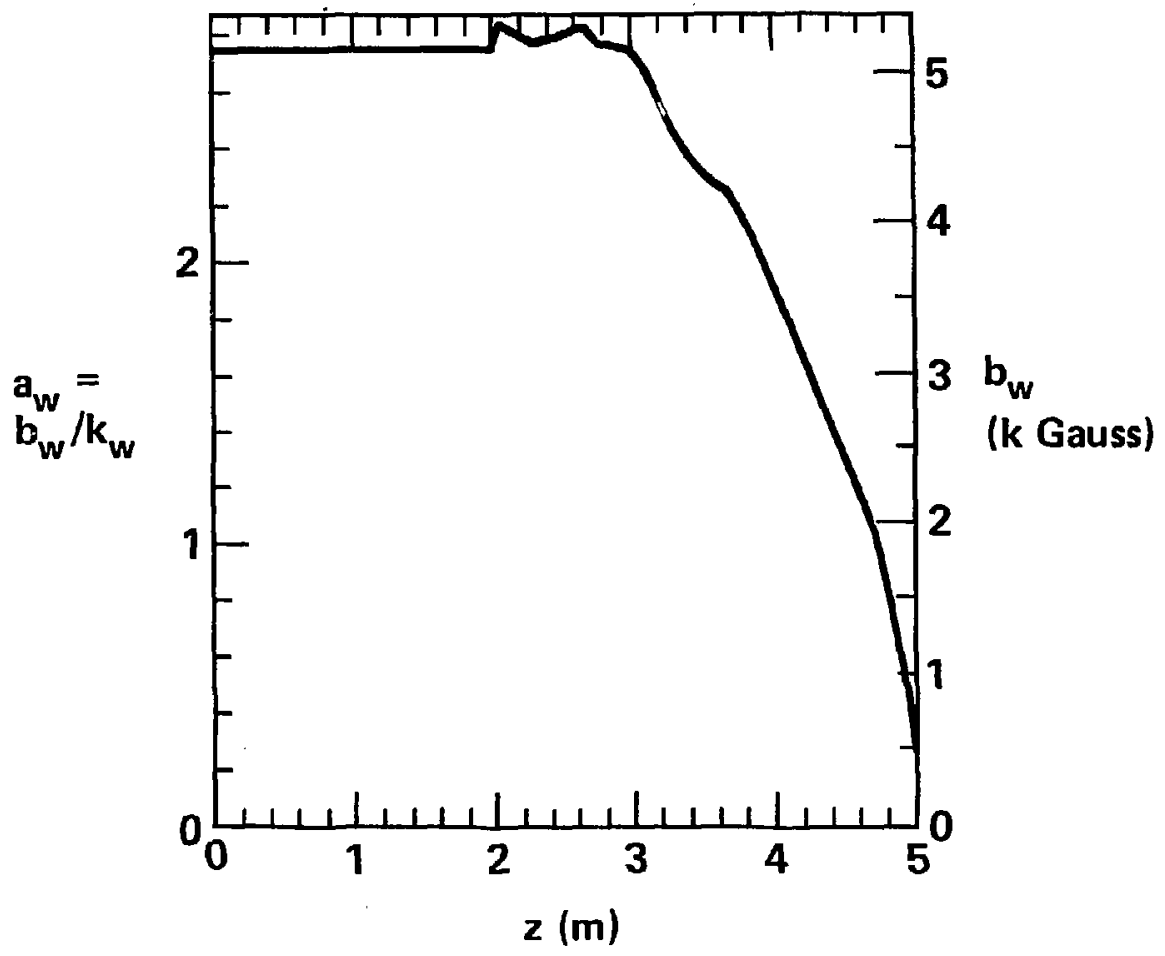

90-F-0287-0134A 
Peak magnetic field vs axial posillon

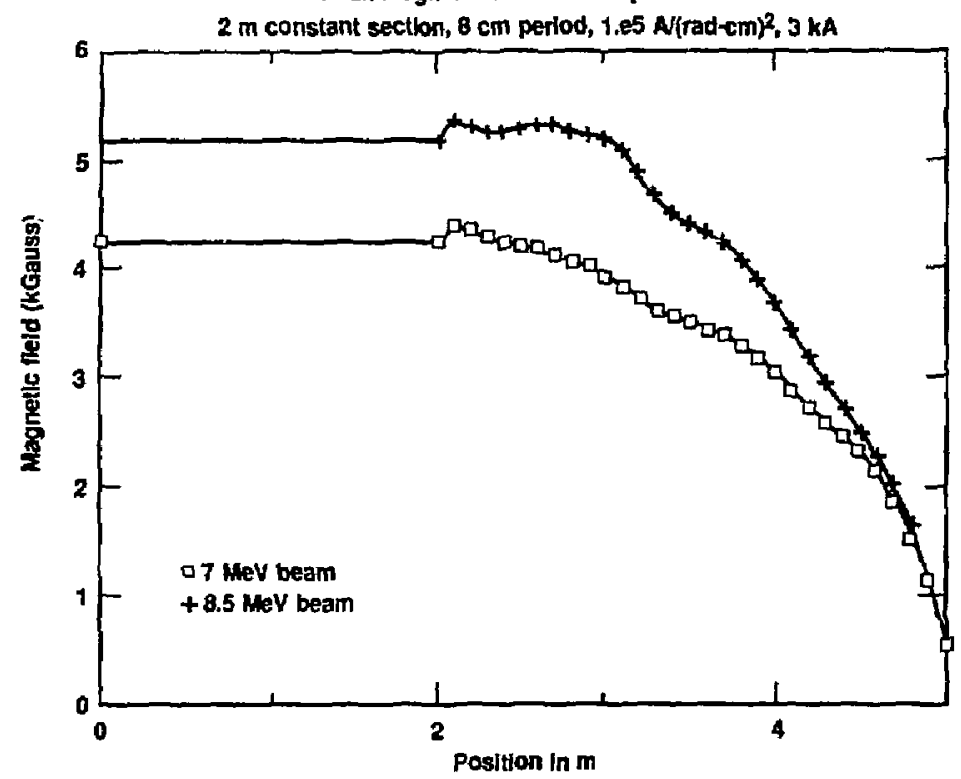

Normallzed vector potential vs axial positton

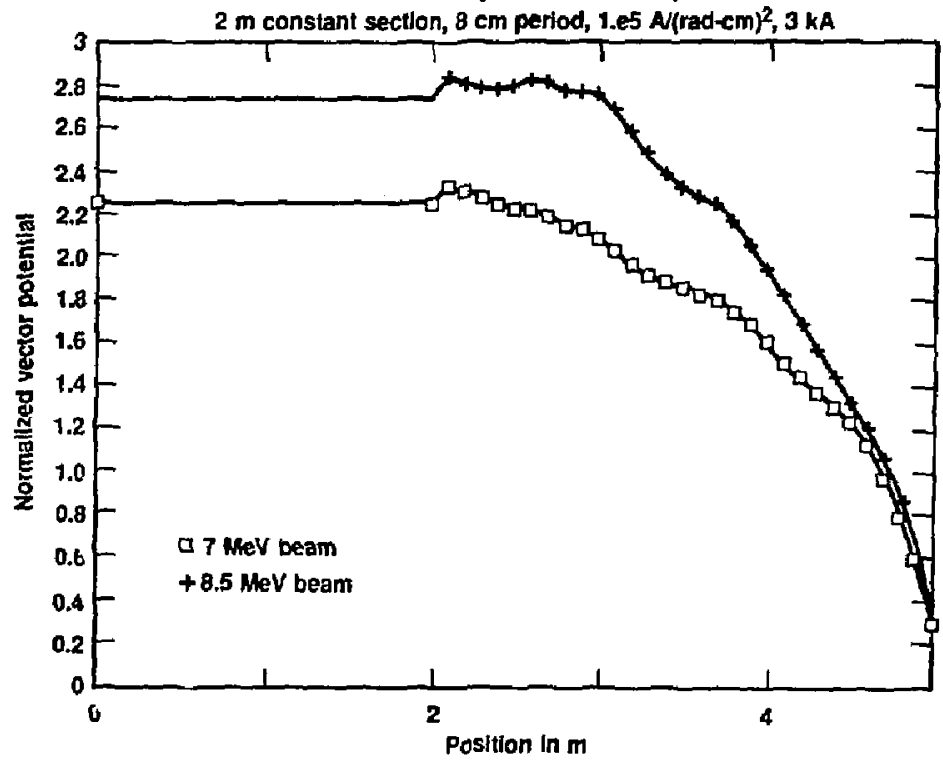

Figure 17 
Sideband power at Z $=.08 \mathrm{~m}$

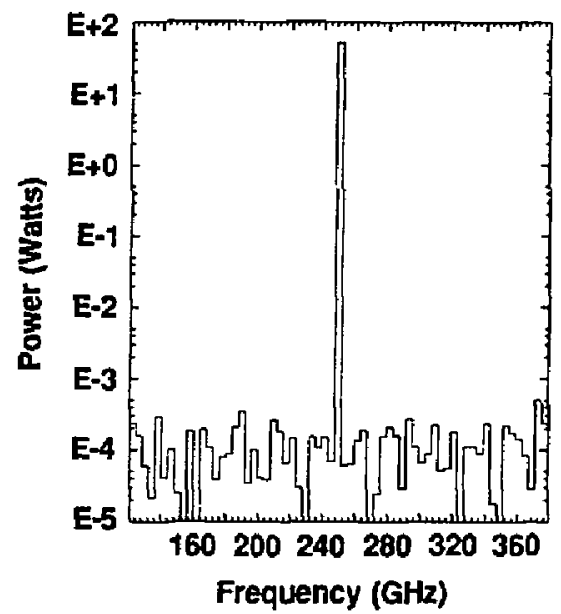

(a)

Output power at $Z=5.04 \mathrm{~m}$

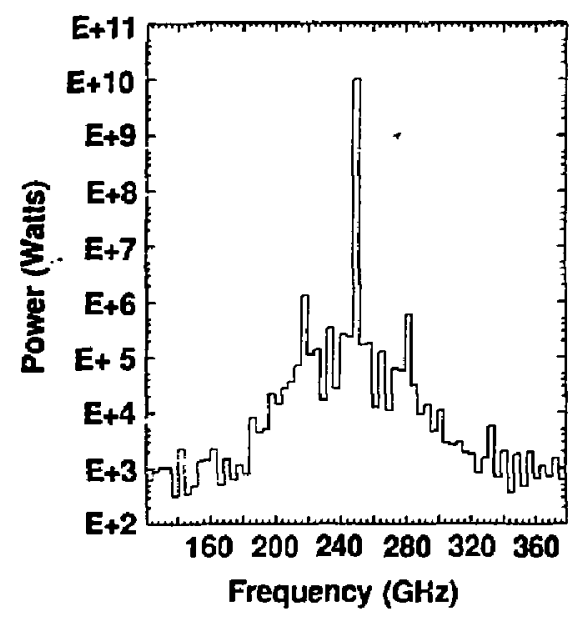

(c)
Sideband power at $Z=2.00 \mathrm{~m}$

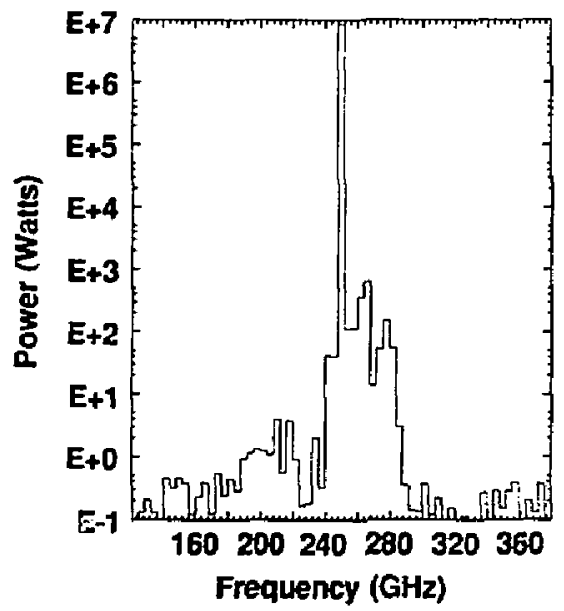

(b)

Relative sideband power vs. $Z$

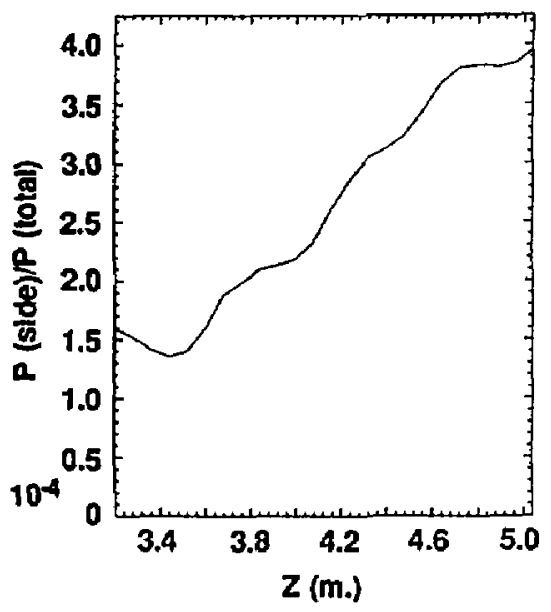

(d) 